\title{
Implementasi Sistem Informasi Pendidikan Muhammadiyah (Sidikmu) Dalam Layanan Administrasi Sistem Pe Nilaian Al Islam, Kemuhammadiyahan Dan Bahasa Arab (Ismuba) Pada Era Industri 4.0 Di Sekolah Dasar Muhammadiyah 1 Krian, Sidoarjo
}

\author{
Muhammad Triandoyo ${ }^{1}$, Isa Anshori ${ }^{2}$ \\ ${ }^{1}$ Program Studi Pendidikan Agama Islam, Universitas Muhammadiyah Sidoarjo, Indonesia \\ ${ }^{2}$ Universitas Islam Negri Sunan Ampel Surabaya, Indonesia dan Universitas Muhammadiyah \\ Sidoarjo, Indonesia \\ muhammadtriandoyo@gmail.com,isaanshori67@gmail.com
}

\begin{abstract}
The development of the world of technology cannot be avoided, educational institutions as centers of education and learning must follow these technological developments so that they can exist more. In the industrial era 4.0 which was marked by advances in information and communication technology, accelerating and providing various kinds of convenience in accessing information and data on various aspects of life. This acceleration and convenience has become a necessity and a lifestyle. Therefore, schools as educational institutions that have various kinds of data must be willing to make changes, adjust to these demands, so that the education and learning process can take place properly, quickly, and accurately. Schools must take advantage of information and communication technology. Carry out the education and learning process online. Consequently, it must have facilities and infrastructure, in the form of information and communication technology. However, the reality in the field is that not all schools have and apply this technology, due to various limitations, financial and workforce quality. The problem then is, is this true, information and communication technology is a major need, without this technology learning cannot take place optimally, the continuity of the institution and its existence is threatened. From here the researcher was moved to research on the implementation of information systems online. Aims to find out and understand the effectiveness of online information system implementation in Era 4.0 as a database and educational information service center at the Krian 1 Muhammadiyah Primary School.

This type of qualitative research uses a phenomenological approach (field research). This study used data collection techniques in the form of observation, interviews, and documents. The collected data were analyzed through 3 stages, namely data collection, data reduction, data presentation, and conclusion drawing. To check the validity of the data, triangulation was used.

The results obtained from this study are the implementation of the Muhammadiyah Education Information System (Sidikmu) in the administrative services of the Al Islam, Kemuhammadiyahan, and Arabic education assessment system in the Industrial era 4.0 at SD Muhammadiyah 1 Krian Sioarjo implemented in integral automation. An information system that not only functions as a database but also as a center for educational information services for student guardians. So that educational institutions can move according to the era which is completely online and instant. Sidikmu is effective and efficient in improving the quality and productivity of the ISMUBA education assessment system administration services at SD Muhamadiyah 1 Krian, Sidoarjo. The effectiveness and efficiency of Sidikmu's work automatically integrate all existing data in schools, making it easier for the administrative process for assessments, especially on ISMUBA subjects. The main obstacle is that not all Ismuba teachers master the technology, so training is needed, the provision of facilities, and guaranteed awards for Creative and Innovative Ismuba teachers
\end{abstract}

Keywords: Era 4.0, Information System, Sidikmu, Assessment System, Ismuba

Abstrak: Perkembangan dunia teknologi tidak dapat dihindari, lembaga pendidikan sebagai
sebagai pusat pendidikan dan pembelajaran harus mengikuti perkembangan teknologi tersebut,
agar bisa lebih eksis. Pada era industri 4.0 yang ditandai dengan kemajuan teknologi informasi
dan kemunikasi, mendorong terjadinya percepatan dan memberikan berbagai macam kemudahan
dalam mengakses informasi dan data pada berbagai aspek kehidupan. Percepatan dan kemudahan
tersebut sudah menjadi kebutuhan dan gaya hidup. Karena itu, sekolah sebagai lembaga
pendidikan yang memiliki berbagai macam data harus bersedia untuk melakukan perubahan-
perubahan, menyesuaikan tuntutan tersebut, agar proses pendidikan dan pembelajarannya bisa 
berlangsung dengan baik, cepat dan akurat. Sekolah harus menfaatkan teknologi infomasi dan komunikasi. Melaksanakan proses pendidikan dan pembelajaran secara daring. Konsekwensinya harus memiliki sarana dan prasarana, berupa teknologi informasi dan komunikasi. Namun kenyataan di lapang, tidak semua sekolah memiliki dan menerapkan teknolgi tersebut, karena berbagai keterbatasan, finansial maupun kualitas ketenagaan. Persoalannya kemudian, apakah memang benar demikian, teknologi informasi dan komunikasi menjadi kebutuhan utama, tanpa teknologi tersebut pembelajaran tidak bisa berlangsung secara optimal, kelangsungan lembaga juga eksistensinya terancam. Dari sinilah peneliti tergerak untuk melakukan penelitian implementasi sistem informasi secara daring. Bertujuan untuk mengetahui dan memahami efektifitas implementasi sistem informasi secara daring pada Era 4.0 sebagai data base dan pusat layanan informasi pendidikan di Sekolah Dasar Muhammadiyah 1 Krian.

Jenis penelitian kualitatif dengan pendekatan fenomenologi (field research). Penelitian ini menggunakan teknik pengumpulan data berupa observasi, wawancara,dan dokumen, Data yang terhimpun dianalisis melalui 3 tahap, yaitu pengumpulan data, reduksi data, penyajian data, penarikan kesimpulan. Untu mengecek keabsahan data digunakan triangulasi.

Hasil yang diperoleh dari penelitian ini adalah implementasi Sistem Informasi Pendidikan Muhammadiyah (Sidikmu) dalam layanan administrasi sistem penilaian pendidikan Al Islam, Kemuhammadiyhan dan Bahasa Arab pada era Industri 4.0 di SD Muhammadiyah 1 Krian Sioarjo diterapkan secara otomatisasi integral. Sistem informasi yang tidak hanya berfungsi sebagai data base tetapi juga sebagai pusat layanan informasi pendidikan untuk Wali Murid. Sehingga lembaga pendidikan mampu bergerak mengikuti zaman yang serba daring dan instan. Sidikmu efektif dan esisien dalam meningkatkan kualitas dan produktifitas layanan administrasi sistem penilaia pendidikan ISMUBA di SD Muhamadiyah 1 Krian, Sidoarjo. Efektifitaas serta efisiensi kerja Sidikmu mengintegrasikan secara automatis seluruh data yang ada di sekolah, sehingga memudahkan dalam proses administrasi penilaian utamanya pada mata pelajaran ISMUBA. Kendala utamanya adalah tidak semua guru Ismuba menguasai teknologi tersebut, sehingga dibutuhkan diklat, penyediaan fasilitas dan jaminan penghargaan bagi guru Ismuba yang Kreatif dan Inovatif.

Kata kunci : Era 4.0, Sistem Informasi, Sidikmu, Sistem Penilaian, Ismuba

\section{PENDAHULUAN}

Ilmu Pengetahuan dan Teknologi (IPTEK) dari masa ke masa senantiasa berkembang. Perkembangan teknologi hendaknya membuat kita terpacu untuk terus belajar agar tidak tertinggal dari bangsa - bangsa lain. Pada era revolusi industri 4.0 yang sebentar lagi akan memasuki era revolusi industri 5.0 ini, perkembangan teknologiInformasi dan Komunikasi semakin maju.[1] Teknologi Infromasi dan Komunikasi menjadi suatu alat penunjang dalam kehidupan sehari-hari yang akan membantu dalam kegiatan apapun. Banyak ayat Al-Qur'an yang menyinggung tentang pengembangan iptek, seperti QS.Al-Ghasiyah, ayat 17-20:[2]

Artinya : Maka tidakkah mereka memperhatikan unta, bagaimana diciptakan?, dan langit, bagaimana ditinggikan?, dan gunung-gunung bagaimana ditegakkan?, Dan bumi bagaimana dihamparkan?.

Menjelaskan tentang pentingnya mengembangkan pemikirannya. Ayat ini berindikasi agar manusia mau berpikir mengenai kekuasaan Allah baik di langit maupun bumi. Dengan memperhatikan ciptaan Allah akan menambah pengetahuan dan wawasan dalam ilmu pengetahuan dan teknologi yang akan sangat bermanfaat untuk kehidupan manusia di bumi. Oleh Karena itu, sangat jelas bahwa manusia dianjurkan untuk terus berfikir dan berkembang, juga pada saat teknologi sudah maju seperti saat ini.

Industri 4.0 ditandai dengan peningkatan digitalisasi manufaktur yang didorong oleh empat faktor: 1) peningkatan volume data, kekuatan komputasi, dan konektivitas; 2) munculnya analisis, kemampuan, dan kecerdasan bisnis; 3) terjadinya bentuk interaksi baru antara manusia dengan mesin; dan 4) perbaikan instruksi transfer digital ke dunia fisik, seperti robotika dan 3D printing. Prinsip dasar industri 4.0 adalah penggabungan mesin, alur kerja, dan sistem, dengan menerapkan jaringan cerdas di sepanjang rantai dan proses produksi untuk mengendalikan satu sama lain secara mandiri. Dari kemajuan teknologi yang sekarang sudah menginjak kepada revolusi industri 4.0, segala sesuatunya dibentuk oleh sistem dengan basis online (daring).[3]

Pada era ini kita bisa melihat bahwa teknologi informasi dan komunikasi dimanfaatkan sepenuhnya di hampir lini kehidupan manusia.[4] Pada era ini hampir seluruh model bisnis mengalami perubahan besar, dari hulu sampai hilir. Kita ketahui bahwa perkembangan pendidikan di dunia saat ini tidak lepas dari adanya perkembangan dari revolusi industri yang terjadi di dunia, 
karena secara tidak langsung perubahan tatanan ekonomi turut merubah tatanan pendidikan di suatu negara.[5]

Pristiandi Teguh Cahya, S.Pd, M.P.Sdm, merupakan Kepala sekolah SD Muhamamdiyah 1 Krian dengan gaya pemikiran yang visioner. Beliau tidak menolak akan kemajuan teknologi namun dapat memanfaadkan dalam sistem kepemimpinan yang dijalankannya. Tahun 2012 SD Muhammadiyah 1 Krian sudah mulai menggunakan sistem informasi pendidikan dengan program Sipinter.

Penerapan teknologi dalam lembaga pendidikan, baik di sekolah maupu madrasah menjadi suatu kebutuhan, bahkan keharusan. Melalui teknologi inilah sekolah dan madrasah bisa menjalankan berbagai aktivitasnya secara efektif dan efisien, meningkatkan kinerja dan budaya kerja,[6] bisa berkembang dengan pesat, dikenal masyarakat dan dunia secara luas, bahkan penentu bagi pilihan masyarakat untuk memasukkan putra putrinya ke lembaga tersebut.[7]

Hasil penelitian bermanfaat untuk mencabar teori manajemen Lembaga Pendidikan Islam terkait dengan pengelolaan Lembaga Pendidikan dengan teknologi sistem layanan administrasi, pembelajaran, informasi dan komunikasi sebagaimana yang dikemukakan oleh Ramayulis yang menyatakan bahwa Manajemen Lembaga Pendidikan Islam merupakan proses pemanfaatan semua sumber daya yang dimiliki baik perangkat keras ataupun lunak yang dilakukan secara efektif, efesien, dan produktif untuk mencapai kebahagiaan dan kesejahteraan baik didunia dan juga di akhirat.[8]

Sekolah visioner adalah sekolah yang mampu berfikir lebih unggul 5 tahun kedepan dari sekolah lain sekolah lain belum memikirkan kami sudah memikirkan, sekolah lain belajar membiasakan disekolah kami sudah terbiasa.[9] Pemikiraan pimpinan sekolah inilah yang melatar belakangan kemajuan dari program yang ada di sekolah untuk menjadi sekolah yang unggul dan bermutu.

Sekolah SD Muhammadiyah 1 Krian merupakan salah satu lembaga pendidikan Muhammadiyah yang selalu mengantisipasi perkembangan masa depan. Tercermin pada program dan layanan pendidikan yang bersaing dan bersanding dengan sekolah internasional, handal dalam menghadapi era global, serta berusaha memenuhi tuntutan kebutuhan pembangunan lokal dan nasional.

Sebagai sekolah dibawah naungan Majels Pendidikan Dasar dan Menengah Muhammadiyah Pimpinan Daerah Muhammadiyah Sidoarjo, SD Muhammadiyah 1 Krian telah melakukan berbagai macam layanan administrasi, termasuk pembelajaran, dengan menggunakan teknologi Informasi Pendidikan Muhammadiyah (SIDIKMU). Dalam hal ini Pendidikan Al Islam, Kemuhammadiyahan dan Bahasa Arab (ISMUBA) merupakan ciri khas utama, sekaligus karakter pembeda dengan sekolah-sekolah lain. Sehingga penerapan teknologi tersebut sangat besar konstribusinya bagi peningkatan kualitas layanan administrasi Pendidikan ISMUBA. Image yang berkembang, biasanya di berbagai sekolah Pendidikan Agama Islam kurang up to date tidak mengikuti perkembangan teknologi.

Dipilihnya SD Muhammadiyah 1 Krian sebagai tempat penelitian dengan alasan SD Muhammadiyah 1 Krian pertama kali yang menerapkan SIPINTER di Indonesia. Suatu sistem informasi yang dipadukan dengan kemajuan teknologi informasi yang dikembangkan di dalam sistem informasi yang handal untuk meningkatkan mutu pendidikan, sehingga menghasilkan informasi yang akurat, up to date dan dapat dinikmati oleh semua pengguna jasa pendidikan dan menjadikan keunggulan dalam memberikan layanan jasa pendidikan. Berkenaan dengan uraian tersebut, maka skripsi ini menganalisis bagaimana "Implementasi Sistem Informasi Pendidikan Muhammadiyah (Sidikmu) dalam Layanan Administrasi Sistem Penilaian Al Islam, Kemuhammadiyahan dan Bahasa Arab pada Era 4.0 di Sekolah Dasar Muhammadiyah 1 Krian”

\section{METODE}

Jenis penelitian ini adalah kualitatif dengan pendekatan fenomenologi. Merupakan penelitian lapangan (field reseach), yaitu suatu jenis penelitian yang dilakukan dengan pengumpulan data yang ada di lapangan. Penelitian kualitatif menghasilkan data deskriptif berupa kata-kata tertulis atau lisan dan perilaku yang diamati .

Fenomenologi mengkaji eksistensi manusia, berusaha mengungkap makna subyektif. Fenomenologi berupaya mencari makna, memposisikan individu sebagai pemberi makna, yang kemudian menghasilkan tindakan dilandasi pengalaman.[10] Istilah paling populer yaitu human as instrumen peneliti sebagai alat untuk mencari data dan menganalisis data yang didapatkan. Karakteristik lain penelitian kualitatif dengan pendekatan fenomenologi adalah peneliti juga terlibat langsung dalam penelitian. Dalam kondisi ini peneliti melakukan interaksi secara langsung dengan subyek penelitian .[11]

Tujuan penelitian ini mengungkap fakta, fenomena, variabel dan keadaan yang terjadi saat penelitian berjalan dan memaparkan data dengan apa adanya. Kegiatan dalam penelitian kualitatif 
ini diantaranya yaitu pengumpulan data, menganalisis data, menginterprestasi data, dan diakhiri dengan sebuah kesimpulan dari analisa data-data yang ada dilapangan.

Dalam penelitian ini subjek penelitian ditentukan secara purposive. terkait "social situation" atau situasi sosial yang terdiri dari tiga elemen yaitu: tempat (place), pelaku (actors), dan aktivitas (activity) yang berinteraksi secara sinergis.[12] Subyek dalam penelitian ini adalah kepala sekolah, waka ismuba, waka kurikulum, waka kesiswaan, tenaga pendidik Ismuba, peserta didik dan wali murid dari SD Muhammadiyah 1 Krian.

Bentuk dan Teknik pengumpulan data yang digunakan adalah pengamatan (observasi), wawancara, dokumen, catatan lapangan, triangulasi. Analisis data yang dilakukan melalui pengumpulan data, reduksi data, penyajian data, penarikan kesimpulan dan verification.[13]

\section{III.HASIL DAN PEMBAHASAN}

A. Implementasi Sistem Informasi Pendidikan Muhammadiyah (Sidikmu) di SD Muhammdiyah 1 Krian

Sistem informasi pendidikan Muhammadiyah (Sidikmu) mulai digunakan oleh SD Muhammadiyah 1 Krian pada tahun 2018. Sidikmu menjadi Sistem Informasi Manajemen Sekolah yang mencakup Akademik, PPDB, pembelajaran daring, ujian online, PPDB, keuangan sekolah, hingga layanan informasi terhadap walimurid. Kepala Sekolah memandang Sidikmu adalah sebuah media, media yang harus dimanfaadkan sebaik mungkin, jika sumber daya manusianya tidak mampu menggunakan media tersebut maka akan sia - sia. Kepala Sekolah yang berperan sebagai manager dari lemabaga pendidikan yang memiliki tugas diantaranya, Planing, Organizing, Actualing dan Evaluating yang diwujudkan dalam kebijakan serta program - program yang dibuat. Dalam hal ini Kepala Sekolah dalam upaya menjalankan Sidikmu telah membuat beberapa program baik untuk admin sekolah, guru, maupun wali murid.

Perwujudan Sidikmu dapat dilihat dari proses administrasi yang terintegrasi dan terkomputerisasi, contohnya pada bagian PPDB. Mekanisme PPDB yang dahulunya manual pembelian formulir menjadi berbasis daring, dengan mekanisme calon wali murid mendapatkan membeli token untuk mengisikan formulir secara daring, dan seluruh informasi menganai PPDB juga dapat diakses melalui daring. Selain itu juga pada aspek administrasi penilaian dalam aspek ini banyak sekali yang berubah dengan adanya Sidikmu. Administrasi penilaian manual memakan waktu yang cukup lama untuk mencapai hasil (raport, daftar kumpulan nilai) sehingga membutuhkan tenaga dan biaya lebih. Mekanisme administrasi penilaian manual seluruh tenaga pendidik merekap nilai yang sudah dikumpulkan, setelah itu dihitung sesuai dengan rumusan untuk menjadi nilai raport dan melihat nilai yang tertinggi dan terendah dari masing - masing siswa untuk menentukan deskripsi raport. Komputerisasi administrasi penilaian yang menggunakan Sidikmu mekanisme kerja tenaga pendidik menginputkan nilai siswa kedalam sistem setelah itu semua sudah terintegrasi dan ter automatisasi sehingga sudah menjadi raport dan menjadi daftar kumpulan nilai. B. Efektifitas dan efisiensi Sistem Informasi Pendidikan Muhamamadiyah pada peningkatan kualitas dan produktifitas layanan administrasi sistem penilaian Pendidikan Al Islam, Kemuhammadiyahan dan Bahasa Arab Era 4.0 di SD Muhammadiyah 1 Krian Sidoarjo

Sidikmu memberikan Sekolah pusat data berbasis daring, yang dapat diakses dimanapun dan kapanpun, tidak terkendala oleh tempat dan waktu memiliki fungsi memberikan media Sistem Informasi Online kepada sekolah sehingga sekolah dapat mengikuti perkembangan zaman saat ini. Sidikmu terutama pada kondisi Pandemi Covid 19 saat ini, adanya pembatasan sosial sekala besar atau PSBB tenaga pendidik tidak menjadi kendala dalam administrasi penilaian karena tidak harus datang di Sekolah untuk mendapatkan data yang diperlukan.

Bentuk administrasi penilaian yang ada pada Sidikmu menyesuaikan dengan aturan kurikulum K13. Penilaian aspek pengetahuan emiliki beberapa jenis evaluasi diantaranya adalah Penilaian Harian (PH), Penilaian Tengah Semester (PTS), dan Penilaian Akhir Semester (PAS). Dalam jenis peniaian tersebut juga ada beberapa bentuk dari penilaiannya diantaranya adalah tulis, lisan, tugas dan remidi. Perbandingan waktu dalam pengerjaan raport sebelum menggunakan Sidikmu dengan sesudah menggunakan Sidikmu. Penggunaan sidikmu terbukti lebih menghemat waktu, hal ini disebabkan karena Sidikmu dapat diakses kapan saja 24 jam tanpa henti. Sehingga tenaga pendidik tidak perlu menunda waktu untuk mengerjakan raport, karena mekanisme pengerjaan raport telah dikerjakan setiap hari dengan cara menginputkan nilai siswa dalam Sidikmu secara real time. Wali Kelas juga tidak butuh waktu jam bekerja untuk dapat melihat apakah nilai dari mata pelajaran ISMUBA sudah masuk di Raport siswa pada kelasnya. Wali Kelas bisa cek kapanpun nilai siswa yang ada di kelasnya walaupun tidak di Sekolah.

Pembuatan raport siswa berbeda ketika menggunakan Raport cara manual, Guru mata Pelajaran ISMUBA harus mencatat nilainya ketika telah melakukan penilaian. Setelah mencatat nilai Guru tersebut harus menghitung nilainya terlebih dahulu agar bisa uncul nilai Raport. Selain itu juga 
Guru harus memilah setiap anak untuk membuat deskripsi KD dari predikat nilai yang telah dihitung untuk menemukan KD yang tertinggi, tengah, dan yang terendah. Setelah nilai Raport sudah dihitung KD sudah di tuliskan, Guru tersebut harus menyetorkan data tersebut kepada Wali Kelas untuk di buat Raport. Disana Wali kelas akan menata kembali dari data yang di berikan oleh Guru mata pelajaran yang lainnya untuk di jadikan satu. Tentu memerlukan waktu yang sangat lama berbeda dengan Sidikmu pertukaran data dapat dilakukan kapanpun dan dimanapun. Selain itu Sidikmu juga memiliki basis data Cloud server sehingga selama ada akses daring, Sidikmu dapat diakses dimanapun dan kapanpun. Tidak harus menggunakan perangkat PC atau Laptop, perangkat yang lain juga dapat digunakan untuk mengakses Sidikmu seperti android / handphone. Hal ini sangat menguntungkan Sekolah terutama pada kondisi Pandemi Covid-19 saat ini.

Efektifitas dan Efisiensi Sidikmu dapat dilihat pada penggunaan Sidikmu pada aspek tenaga lebih sedikit dibutuhkan dibandingkan dengan manual dalam hal mencapai tujuan yang telah direncanakan hal ini menunjukkan bahwa dari segi tenaga Sidikmu lebih efisien dibandingkan manual. Pada aspek biaya Sidikmu dalam administrasi penilaian tidak membutuhkan biaya sama sekali berbeda dengan manual yang membutuhkan intensif untuk akomodasi dan terkadang juga waktu lembur kerja beberapa tenaga pendidik. Selain itu dari aspek waktu Sidikmu tidak membutuhkan waktu yang lama. waktu yang dibutuhkan oleh Sidikmu untuk bekerja sangat singkat dan mampu meringkas pekerjaan dari tenaga pendidik, karena semua sudah terintegrasikan dalam sistem ketika pendidik menginputkan nilainya setiap proses pelaksanaan penilaian, berbeda dengan manual Bapak dan Ibu Guru harus mengolah terlebih dahulu nilai yang telah dikumpulkan sehingga bisa menjadi raport, hal ini menunjukkan bahwa Sidikmu lebih efisien dalam aspel waktu. Pada capaian tujuan Sidikmu lebih banyak mencapai tujuan karena Sidikmu membuat automatis ketika input dijalankan data secara langsung di proses menjadi berbagai macam hasil contohya pada penialaian adalah Raport, Daftar Kumpulan Nilai, dan Layanan Informasi kepada Wali Murid di aplikasi android. paparan di atas membuktikan, bahwa penerapan Sidikmu efektif dan efisien dalam menngkatkan kualitas dan produktifitas layanan administrasi Sistem Penilaian Pendidikan Al Islam, Kemuhammadiyahan dan Bahasa Arab.

C. Hambatan dan Solusi dalam Implementasi Sistem Pendidikan Muhammadiyah pada peningkatan kualitas dan produktifitas layanan administrasi sistem penilaian Pendidikan Al Islam, Kemuhammadiyahan dan Bahasa Arab Era 4.0 di SD Muhammadiyah 1 Krian Sidoarjo

Semua program sekolah pasti memiliki kendala yang harus ditemukan solusinya guna untuk mencapai yang lebih baik. Begitu juga dengan Sidikmu, pada pelaksanaan Sidikmu pasti memiliki kendala, namun hal tersebut sudah dipersiapkan oleh Kepala Sekolah. Setiap pekannya Kepala Sekolah bersama dengan Kepala Urusan (Kaur) mengadakan rapat evaluasi pada setiap bidang salah satunya adalah Sidikmu. Selain itu juga Kepala Sekolah mendatangkan Customer Service (CS) Sidikmu setiap bulannya untuk monitoring Sekolah dalam menjalankan Sidikmu. Ada beberapa klasifikasi kendala yang ada dalam pelaksanaan Sidikmu dibedakan berdasarkan akunnya, diantaranya yakni :

1. Sekolah

Kendala yang dihadapi oleh sekolah adalah berkaitan dengan alur proses kerja maupun output dari Sidikmu. Contohnya adalah persentase pada proses penilaian, Raport UAS dan PTS, format daftar kumpulan nilai. Karena adanya perbedaan prosentasi penilaian yang biasa digunakan dengan yang ada di Sidikmu sehingga harus dirubah oleh developer Sidikmu, begitujuga dengan raport dan daftar kumpulan nilai siswa.

2. Guru

Kendala yang dihadapi oleh tenaga pendidik adalah kendala teknis kesalahan mengisi form atau juga menganai keamanan akun. Selain itu juga ada beberapa guru yang kesulitan terhadap penggunaan pembelajaran daring karena tidak terbiasa dengan hal tersebut, terutama pada tenaga pendidik agama yang latar belakang pendidikannya adalah madrasah atau pondok pesantren sehingga kurang dalam mengenal TIK. Hal ini penanganan langsung kepada admin Sidikmu yang ada di sekolah yang sebelumnya telah dilatih oleh tim Sidikmu. Sehingga kendala langsung tertangani dengan cepat sehingga tidak menghambat kerja dari tenaga pendidik.

3. Wali Murid

Kendala yang dihadapi oleh wali murid adalah lupa terhadap akun anaknya, sehingga tidak dapat mengakses informasi terbaru. Selain itu juga terhadap wali murid yang kurang mengenal tentang android sehingga kesulitan dalam mengakses atau menggunakan pembelajaran daring, sehingga memerlukan pembiasaan serta kemauan agar dapat terbiasa dengan sistem daring. Kendala ini dapat langsung dikomunikasikan oleh admin sekolah yang dapat dihubungi setiap saat.

Sekolah memahami bahwa kendala yang ada pada Sidikmu merupakan sesuatu yang harus dibiasakan, karena dengan hadirnya sistem informasi yang baru akan mengubah sistem kerja yang 
ada. Kepala Sekolah dengan menghadirkan Sistem Informasi ini merupakan upaya untuk memudahkan pekerjaan administrasi pendidikan agar dapat lebih fokus terhadap inovasi media serta metode dalam pembelajaran.

\section{KESIMPULAN}

Dari berbagai uraian di atas menunjukkan bahwa:

1. Implementasi Sidikmu dalam layanan administrasi sistem penilaian Al Islam, Kemuhammadiyahan dan Bahasa Arab di SD Muhammadiyah 1 Krian dilakukan melalui otomatisasi, sesuai dengan era industri 4.0 yang membuat sekolah menjadi berbasis IT. Sistem penilaian Pendidikan Al Islam, Kemuhammadiyah dan Bahasa Arab terintegrasi dengan sistem penilaian sekolah, terintegrasi dengan nilai-nilai mata pelajaran yang lainnya, dengan data siswa, data guru, keuangan, PPDB, pembelajaran daring, ujian daring, Raport, dan Layanan Informasi. Semua terintegrasi didalam Sidikmu. Administrasi Penilaian berubah dengan adanya Sidikmu. Jika sebelumnya manual dari mencatat nilai dalam Buku Nilai setelah itu diolah lagi dengan mengumpulkan nilai dari guru mata pelajarannya yang lain, namun sekarang tidak perlu mencatat nilai langsung di inputkan ke dalam Sidikmu, setelah itu Sidikmu sudah automatis memperogram untuk Raport, DKN dan juga menu Nilai Siswa yang ada di Android Wali Murid.

2. Efektifitas dan efisiensi Sidikmu pada peningkatan kualitas dan produktifitas layanan administrasi sistem penilaian pendidikan Al Islam, Kemuhammadiyahan dan Bahasa Arab di SD Muhammadiyah 1 Krian tergambar pada capaian tujuan, penghematan waktu, tenaga dan biaya. Siswa bisa melihat nilaianya secara langsung melalui web atau hp yang dimiliki. Orang tua dapat melihat nilai ISMUBA anaknya dalam aplikasi Sekolah. Tidak hanya nilai tetapi juga materi, tanggal penilaian serta aspek penilaiannya yang dapat dilihat sehingga Wali murid mengetahui informasi secara lengkap tentang nilai tersebut guna untuk melihat sejauh mana pemahaman dalam mata pelajaran ISMUBA. Selain itu juga menghemat pekerjaan dalam pembuatan Raport, karena Guru mapel ISMUBA tinggal menginputkan nilai kedalam Sidikmu sudah automatis menjadi DKN (daftar kumpulan nilai) ke Kurikulum, nilai Raport beserta Deskripsinya ke Wali Kelas.

3. Hambatan dalam implementasi Sidikmu sebagai layanan administrasi sistem penilaian pendidikan ISMUBA di SD Muhammadiyah 1 Krian adalah, banyak pengguna yang sering melupakan kata sandi untuk akunya. Selain itu Sekolah memiliki karakterisktik tersendiri dalam format Raport sehingga Sidikmu perlu menyesuaikan. Solusi yang dihadirkan Sekolah untuk menindak lanjuti hambatan yang ada adalah dengan menghadirkan tim Sidikmu setiap bulannya untuk memonitoring Sidikmu di Sekolah. Admin Sekolah selaku administrator dalam Sidikmu dilatih secara menyeluruh serta diberikan pemahaman tentang alur berjalannya Sidikmu sehingga dapat memberikan solusi dari masalah yang dihadapi Bapak Ibu Guru serta Wali murid. Kepala Sekolah setiap pekannya mengadakan rapat yang membahas kendala sekolah termasuk Sidikmu guna untuk mengetahui kondisi dari implementasi Sidikmu

Penelitian ini menemukan bahwa Pemanfaatan Teknologi Informasi Pendidikan yakni Sistem Informasi Pendidikan Muhammadiyah (SIDIKMU) efektif dan efisien dalam peningkatan kualitas dan produktifitas layanan administrasi Sistem Penilaian Pendidikan Al Islam, Kemuhammadiyaah dan Bahasa Arab. Temuan ini secara teoritis berimplikasi pada pengembangan teori Ramayulis yang menyatakan bahwa Manajemen Lembaga Pendidikan Islam merupakan proses pemanfaatan semua sumber daya yang dimiliki baik perangkat keras ataupun lunak yang dilakukan secara efektif, efesien, dan produktif untuk mencapai kebahagiaan dan kesejahteraan baik didunia dan juga di akhirat. Dalam hal ini, bila dikaitkan dengan manajemen lembaga pendidikan Muhammadiyah, melalui SIDIKMU, otomatisasi sistem penilaian dalam ISMUBA memungkikan para guru Ismuba untuk bisa berkreasi mengembangkan materi dan model pembelajaran Al Islam, Kemuhammadiyahan dan Bahasa Arab. Waktu guru tidak lagi dihabiskan untuk menangani administrasi penilaian, Kreasi guru tersebut menjadikan pembelajaran lebih menarik, kualitas proses dan hasil belajar ISMUBA juga akan terus mengalami peningkatan. Bila ini terjadi, pembentukan kader persyarikatan yang menjadi amanah setiap sekolah Muhammadiyah bisa diwujudkan. Berarti penguasaan teknologi bagi para guru Ismuba menjadi sangat penting, harus difasilitasi oleh kepala sekolah, baik menyangkut ketersediaan fasilitas teknologi, pelatihanpelatihan yang diperlukan, maupun pengembangan dan penghargaan guru-guru ISMUBA yang kreatif dan inivatif.

\section{UCAPAN TERIMAKASIH}

Terselesaikanya jurnal ini tidak pula terlepas dari bantuan dan dukungan dari berbagai pihak baik secara langsung maupun tidak langsung. Untuk itu pada kesempatan ini, peneliti ingin mengucapkan terima kasih sebesar-besarnya kepada: 
1. Bapak Dr. Hidayatullah. M.Si selaku Rektor Universitas Muhammadiyah Sidoarjo beserta para dosen, asisten dan segenap karyawan di lingkungan Universitas Muhammadiyah Sidoarjo.

2. Ibu Dr. Istikomah, M. Ag selaku dekan fakultas Agama Islam Universitas Muhammadiyah Sidoarjo

3. Ibu Anita Puji Astutik, S.Ag., M.Pd.I selaku dosen wali dan kaprodi pendidikan agama Islam yang telah memberikan dukungan dan pengaharan selama masa perkuliahan

4. Kedua orang tua saya, teurtama ibu saya tercinta yang tidak pernah lelah memberikan kasih sayangnya terhadap saya serta selalu mendukung selama masa pendidikan sampai saat ini

5. Seluruh teman-teman pendidikan Agama Islam seperjuangan, kawan-kawan IMM Averroes dan KOORKOM UMSIDA, teman-teman saya yang telah banyak memberikan semangat, motivasi dan do'a

6. Bapak kepala sekolah, kepala bagian kurikulum, kepala bagian humas dan seluruh keluarga besar SD Muhammadiyah 1 Krian yang telah memberikan kesempatan penulis untuk mengadakan penelitian dengan memberikan informasi dan data yang penulis perlukan dalam menyelesaikan skripsi ini

Penulis tidak bisa memberikan apapun sebagai tanda terimakasih. Hanya do'a tulus kepada Allah Swt yang dapat penulis panjatkan untuk semua pihak yang telah banyak membantu. Semoga amal baik yang dilakukan mendapat balasan berlipat ganda dan diterima sebagai amal shalilh. Peniliti sadar bahwa penulisan tugas akhir ini masih ada kekutangan. Akhirnya peneliti mengharapkan masukan berupa saran dan kritik yang membangun dan pembaca demi penyempurnaan skripsi ini dan khusunya guna memaksimalkan serta pengembangan Fakultas Agama Islam Universitas Muhammadiyah Sidoarjo di masa mendatan demi tercapainya tujuan pendidikan nasional.

\section{REFERENSI}

[1] Isa Anshori \& Suwidiyanti, Improvement of Mathematics Teacher Performance ThroughAcademic Supervision With Collaborative Approaches.IJERE: International Journal of Educational Research Review, 5 (3), July 2020, Pages: 227, DOI: 10.24331/ijere.735935

[2] Kemenag, (2002), Al Qura'an, 88:17-5.

[3] Afandi \& Sajidan. Stimulasi Keterampilan Tingkat Tinggi. (Surakarta: UNSPRESS, 2017), 6.

[4] Kasali, R. Disruption (9th ed.). (Jakarta: Gramedia, 2018), 74.

[5] Eko Risdianto. Analisis Pendidikan Indonesia di Era Revolusi Industri 4.0. (https://www.academia.edu/38353914/Analisis_Pendidikan_Indonesia_di_Era_Rev

olusi_Industri_4.0.pdf, diakses tanggal 22 Nopember, 2019), 3.

[6] Isa Anshori, Penerapan Nilai Budaya Kerja: Peluang dan Tantangan bagi peningkatan Kinerja Madrasah, Cendekia: Jurnal Pendidikan dan Humaniora, 2 (3), Juli- Desember 2018), hal 192-201. [7] Isa Anshori, Perilaku Memilih Lembaga Pendidikan: Perspektif Teori Rational Choice dan Bonded rational, Prosiding Seminar Nasional Pendidikan: Thema "Desain Pembelajaran di Era Asean Economic Community (AEC) untuk Pendidikan Indonesia Berkemajuan," (Sidoarjo: Fakultas Keguruan dan Ilmu Pendidikan Universitas Muhammadiyah Sidoarjo, 2017), 136-160.

[8] Ramayulis, Ilmu Pendidikan Islam, (Jakarta: Kalam Mulia, 2008), 274.

[9] Andi teca, Manajemen Unik, (Yogyakarta: Titah Surga, 2016), 13.

[10] Isa Anshori, Melacak State of Thi Arth Fenomenologi dalam Kajian Ilmu Sosial, (Halaqa: Islamic Educational Journal, 2 (2), 2018), 165.

[11] Musfiqon H. M., Panduan Lengkap Metodologi Penelitian Pendidikan (Jakarta: Prestasi Pustaka, 2012), 71.

[12] Sugiyono, Metode Penelitian Kuantitatif, Kualitatif, dan R\&D, (Bandung: Al Fabeta, 2014), 215.

[13] Ahmadi Rulam, Metodologi Penelitian Kualitatif, (Yogyakarta:Ar-Ruzz Media, 2016), 179. 